\title{
Presence of mecA-positive multidrug-resistant Staphylococcus epidermidis in bovine milk samples in Brazil
}

\author{
Fernanda Fernandes dos Santos, ${ }^{*}$ Letícia Caldas Mendonça, $†$ Daniele Ribeiro de Lima Reis, $†$ \\ Alessandro de Sá Guimarães, † Carla Christine Lange,† João Batista Ribeiro,† Marco Antonio Machado,† \\ and Maria Aparecida Vasconcelos Paiva Brito ${ }^{1}$ \\ ${ }^{*}$ Federal University of Juiz de Fora, Rua José Lourenço Kelmer, 36036-330 Juiz de Fora, Minas Gerais, Brazil \\ †Embrapa Dairy Cattle Research Center, Rua Eugênio do Nascimento, 610, Bairro Dom Bosco, 36038-330 Juiz de Fora, MG, Brazil
}

\begin{abstract}
Bacteria of the genus Staphylococcus are one of the major pathogens causing bovine mastitis. In recent decades, resistance of this genus to oxacillin (methicillin) has been a matter of concern due to the possibility of reducing the effectiveness of mastitis treatments and the transfer of resistance determinants to other bacteria. Oxacillin resistance was studied in 170 staphylococci from bovine milk samples, including 79 Staphylococcus aureus and 91 coagulase-negative staphylococci (CNS). The susceptibility profile of 10 antimicrobial agents used in veterinary practice was determined by the Etest method. In addition to the Etest, the phenotypic characterization of oxacillin resistance was tested using the cefoxitin disk diffusion test. All isolates were screened by PCR to detect the mecA gene in 2 different regions of the gene. The isolates with an oxacillin minimum inhibitory concentration $\geq 0.5 \mu \mathrm{g} /$ $\mathrm{mL}$ or resistant to cefoxitin were identified by sequencing a 536-bp fragment of the $16 \mathrm{~S}$ rRNA gene. This group of isolates was also evaluated for the presence of bla $Z$ and mecC genes. Molecular analysis of the mecA gene was carried out by typing of the staphylococcal cassette chromosome mec (SCCmec). The relatedness of the mecA-positive isolates was evaluated by macrorestriction of chromosomal DNA followed by pulsed-field gel electrophoresis. With the exception of penicillin and oxacillin, $86 \%$ of the isolates showed susceptibility to cephalothin, gentamicin, erythromycin, sulfonamide, trimethoprim-sulfamethoxazole, and tetracycline. All $S$. aureus isolates were susceptible to oxacillin, whereas $47 \%$ ( $\mathrm{n}=43)$ of the CNS isolates were resistant. The CNS isolates showed a higher resistance to cephalothin, erythromycin, tetracycline, and gentamicin in comparison with $S$. aureus. The mecA gene was only detected in $10 \mathrm{CNS}$ isolates, identified as Staphylococcus epi-
\end{abstract}

Received June 9, 2015.

Accepted October 1, 2015.

${ }^{1}$ Corresponding author: maria.brito@embrapa.br dermidis, and classified into 3 pulsotypes (A, B, and $\mathrm{C})$ and 4 subtypes (A1, B1, B2, and B3). Among the isolates with an oxacillin resistance phenotype, 12 were positive for the blaZ gene, and 9 of them were mecApositive. Two of the oxacillin-resistant isolates amplified the mecA homolog gene of Staphylococcus sciuri and none amplified mecC. Three SCCmec types, I, IV, and V, were found. Our results suggest that Staphylococcus epidermidis can be a reservoir for mecA for other Staphylococcus species. Studies investigating the molecular and phenotypic profile of antimicrobial resistance in staphylococcal species should be performed for controlling the spread of resistance and the selection of appropriate therapeutic measures.

Key words: antimicrobial resistance, methicillinresistant staphylococci, mecA, SCCmec

\section{INTRODUCTION}

Bovine mastitis, defined as inflammation of the mammary gland, is one of the most important diseases in dairy production systems because it causes substantial economic losses to the milk industry worldwide. In addition to adversely affecting the production and quality of milk, clinical cases have major implications for reducing the well-being of the affected animals (Viguier et al., 2009). Among the various microorganisms that have been reported, bacteria of the genus Staphylococcus are the most commonly found as a cause of bovine mastitis (Kalmus et al., 2011; Persson et al., 2011).

Staphylococcus aureus represents a major agent of contagious bovine mastitis, whereas CNS have traditionally been considered to be minor pathogens. Currently, CNS is one of the main groups of microorganisms isolated from bovine subclinical intramammary infections in several countries (Botrel et al., 2010; Kalmus et al., 2011; Persson et al., 2011). Strains of Staphylococcus chromogenes, Staphylococcus simulans, Staphylococcus haemolyticus, Staphylococcus xylosus, and Staphylococcus epidermidis may remain in the udder, causing a low to moderate increase in SCC and possibly leading to a 
slight decrease in milk production (Vanderhaeghen et al., 2014).

The majority of bovine mastitis pathogens are susceptible to the antimicrobials used for treatment, but some studies have indicated an augmented resistance of $S$. aureus and CNS to $\beta$-lactam antibiotics, especially to penicillin and ampicillin (Botrel et al., 2010; Kalmus et al., 2011; Persson et al., 2011). In recent decades, the emergence of methicillin resistance among staphylococci isolated from bovine milk has been reported in different countries and continents (Holmes and Zadoks, 2011).

The resistance to methicillin is conferred by the production of the penicillin-binding protein (PBP) 2a or 2 ', which has a low affinity for $\beta$-lactam antibiotics. The mecA gene, which encodes PBP2a, is carried by a mobile genetic element, the staphylococcal cassette chromosome mec (SCCmec). The SCCmec contains the mec complex genes, encoding mecA, its regulators, and the $c c r$ gene complex, which encodes site-specific recombinases that are responsible for the mobility of the element. The remaining part of the $S C C m e c$ is the $\mathrm{J}$ region ( $\mathrm{J} 1, \mathrm{~J} 2$, and $\mathrm{J} 3$ ), which is not considered as an essential component, although this region may contain genes conferring resistance to other antimicrobials (Becker et al., 2014). The SCCmec elements are classified into types by the combination of the $\mathrm{ccr}$ gene complex and the class of mec gene complex (IWG-SCC, 2009). Currently, 11 types of SCCmec (I-XI) have been defined in S. aureus (Milheiriço et al., 2007; Becker et al., 2014). Recently, a new divergent mecA homolog $(m e c C)$ was described in a novel SCCmec designated as type XI. The $m e c C$ gene encodes a PBP with a $63 \%$ identity with PBP2a at the amino acid level. It was described in an $S$. aureus strain isolated from bovine milk that was phenotypically resistant to oxacillin but not harboring the mecA gene (García-Álvarez et al., 2011).

The genetic analysis of staphylococci indicates that transfer of these microorganisms among animals and humans as well as the horizontal transfer of resistance genes can occur (Becker et al., 2014). The emergence of $S$. aureus carrying mecA gene in dairy cattle may be related to contact with related species, such as CNS (Holmes and Zadoks, 2011). Furthermore, due to the possibility of acquisition of resistance to multiple antibiotics, methicillin-resistant staphylococci may be a future problem for both the treatment of infections in humans and the treatment of bovine mastitis.

The importance of surveillance of methicillin-resistant staphylococci and the accurate diagnosis of these bacteria is paramount for appropriate mastitis treatment. For that reason, the purpose of this study was to assess the antimicrobial resistance and characterize the methicillin resistance of $S$. aureus and CNS isolated from bovine milk, showing oxacillin inhibition zone diameter of $\leq 13 \mathrm{~mm}$ and of $\leq 18 \mathrm{~mm}$, respectively, in the disk diffusion test.

\section{MATERIALS AND METHODS}

\section{Bacterial Isolates}

The tested Staphylococcus isolates were obtained from a previous longitudinal study that monitored the antimicrobial resistance of udder pathogens in 6 Brazilian states carried out from 2008 to 2010. In the study, 91 dairy herds were visited 4 times, every 6 mo, to aseptically collect milk samples before milking. A total of 28,672 composite milk samples from lactating purebred Holstein cows or crossbred Holstein/Zebu of 1/2, 3/4, and $5 / 8$ Holstein content were collected. These animals showed different lactation periods, ranging from the first to the ninth month after parturition. Cows that were treated with antimicrobials were excluded from the sampling. The milk samples collection and the bacterial isolation were performed according to the $\mathrm{Na}$ tional Mastitis Council (NMC, 2004). A total of 1,365 S. aureus and 1,484 CNS were isolated and subjected to the disk diffusion antimicrobial susceptibility tests.

To examine methicillin resistance, 170 staphylococci, including 79 (5.8\%) S. aureus and 91 (6.1\%) CNS were selected among isolates obtained from 48 dairy herds located in the following states: Minas Gerais (n isolates $=4$ ), Pernambuco ( $\mathrm{n}$ isolates $=3$ ), Paraná ( $\mathrm{n}$ isolates $=27$ ), Rio Grande do Sul ( $\mathrm{n}$ isolates = 11), Santa Catarina ( $\mathrm{n}$ isolates $=56$ ), and São Paulo ( $\mathrm{n}$ isolates $=69$ ). The isolates were selected based on an oxacillin inhibition zone diameter of $\leq 13 \mathrm{~mm}$ for $S$. aureus and of $\leq 18 \mathrm{~mm}$ for CNS. The isolates were identified as $S$. aureus and CNS according to colony morphology on blood agar ( $5 \%$ defibrinated sheep blood, agar base: Tryptone Soya, Oxoid, Basingstoke, UK), Gram staining, production of catalase and acid from glycerol, resistance to furazolidone (100 $\mu \mathrm{g}$ disk, Oxoid), and tube coagulase test using rabbit plasma (Laborclin, Curitiba, Brazil). Staphylococcus aureus differentiation from coagulase-positive staphylococci was performed by the acetoin production (NMC, 2004).

\section{Phenotypic Antimicrobial Susceptibility Testing}

Minimum inhibitory concentration (MIC) was determined by the Etest in accordance with the manufacturer's instructions (Biomérieux, RCS Lyon, France) and the Clinical and Laboratory Standards Institute (CLSI) recommendations specified in the CLSI document VET01 A4 (CLSI, 2013a). Ten antimicrobials were 
tested: cephalothin, clindamycin, enrofloxacin, erythromycin, gentamicin, oxacillin, penicillin, sulfamethoxazole, tetracycline, and trimethoprim-sulfamethoxazole. Mueller Hinton agar plates (Oxoid) were streaked with the bacterial suspensions adjusted to the $0.5 \mathrm{McF}$ arland turbidity standard and incubated at $35^{\circ} \mathrm{C}$ for 18 to 24 $\mathrm{h}$. The MIC value was visually recorded using a magnifying glass at the point where the edge of the growing culture intersected the antimicrobial strip. Staphylococcus aureus ATCC 29213 was included in each batch of isolates as a test for quality control.

To compare the differences between the MIC values obtained for $S$. aureus $(\mathrm{n}=79)$ and CNS $(\mathrm{n}=91)$, the susceptibility breakpoints were determined as described in CLSI document VET01-S2, Table 2B (CLSI, 2013b), that is, cephalothin: $\geq 32 \mu \mathrm{g} / \mathrm{mL}$, erythromycin: $\geq 8 \mu \mathrm{g} /$ mL, gentamicin: $\geq 16 \mu \mathrm{g} / \mathrm{mL}$, oxacillin: $\geq 4 \mu \mathrm{g} / \mathrm{mL}(S$. aureus) and $\geq 0.5 \mu \mathrm{g} / \mathrm{mL}$ (CNS), penicillin: $\geq 0.25 \mu \mathrm{g} /$ $\mathrm{mL}$, sulfamethoxazole: $\geq 512 \mu \mathrm{g} / \mathrm{mL}$, tetracycline: $\geq 16$ $\mu \mathrm{g} / \mathrm{mL}$, and trimethoprim-sulfamethoxazole: $\geq 4 / 76$ $\mu \mathrm{g} / \mathrm{mL}$. The isolates were not classified as susceptible or resistant to clindamycin and enrofloxacin because the CLSI breakpoints were not available in the table mentioned above.

The MIC results were determined based on 2-fold dilutions centered around $1 \mu \mathrm{g} / \mathrm{mL}$. Half-log MIC values were rounded to the next higher value on the standard 2-fold dilution series (Schwarz et al., 2010). Isolates with MIC in the intermediate range were categorized as resistant for data analysis. Differences observed in the percentage of antimicrobial susceptibility among the $S$. aureus and CNS isolates were compared by the chisquared test. A Staphylococcus isolate was considered multidrug-resistant (MDR) if it was phenotypically resistant to 3 or more classes of the antimicrobial agents (Schwarz et al., 2010).

Susceptibility to cefoxitin was assessed by the disk diffusion method (Oxoid, Hampshire, UK). Staphylococcus aureus isolates $(\mathrm{n}=79)$ were considered resistant when the inhibition zone was $\leq 21 \mathrm{~mm}$, and for CNS isolates $(\mathrm{n}=91)$ the inhibition zone was $\leq 24$ mm (CLSI, 2013a). Staphylococcus aureus ATCC 25923 was used in each batch of isolates as a test for quality control.

\section{mecA, mecC, blaz, 16S rRNA, and SCCmec Typing PCR Assays}

The DNA extractions were carried out according to Lange et al. (2015). Cell lysis was achieved by lysostaphin and lysozyme treatments (Sigma, St. Louis, $\mathrm{MO})$.
All isolates (79 S. aureus and $91 \mathrm{CNS}$ ) were tested by PCR for the mecA gene using primers that amplify different regions of the gene (Murakami et al., 1991; Mehrotra et al., 2000). An S. epidermidis mecA-positive control strain was provided by G. M. Costa (Federal University of Lavras, Lavras, MG, Brazil), and S. aureus ATCC 25923 was used as a negative control. All CNS showing an oxacillin MIC $\geq 0.5 \mu \mathrm{g} / \mathrm{mL}$ by Etest or classified as resistant by the cefoxitin disk diffusion test were tested for the presence of the blaZ and mecC genes using singleplex PCR according to Gao et al. (2011) and García-Álvarez et al. (2011), respectively, and identified by sequencing a 536-bp fragment of $16 \mathrm{~S}$ rRNA (Lange et al., 2015). Primers for the conserved regions of the staphylococcal $16 \mathrm{~S}$ rRNA were used in the PCR reactions of mecA, mecC, and blaZ as internal controls (Jaffe et al., 2000). The PCR final volume was $50 \mu \mathrm{L}$, containing $45 \mu \mathrm{L}$ of PCR MasterMix (Ludwig Biotech, RS, Brazil; in mecA, mecC, and bla $Z$ reactions) or $47 \mu \mathrm{L}$ (in $16 \mathrm{~S}$ rRNA sequencing reactions), $1 \mu \mathrm{L}$ of each primer $(10 \rho \mathrm{mol} / \mu \mathrm{L})$, and $1 \mu \mathrm{L}$ of the DNA template (300 ng). After amplification, the PCR products $(10 \mu \mathrm{L})$ were electrophoresed in a $1.5 \%$ agarose gel at $100 \mathrm{~V}$ for $45 \mathrm{~min}$, stained with ethidium bromide $(0.5$ $\mu \mathrm{g} / \mathrm{mL}$ ), and photographed under UV light.

The SCCmec was typed using a multiplex PCR protocol described by Milheiriço et al. (2007). This reaction was performed with mecA-positive isolates only.

\section{DNA Sequencing}

The PCR products obtained for the resistance genes mecA, mecC, blaZ, and $16 \mathrm{~S}$ rRNA were sequenced to confirm their identity after purification by the Easy Gen kit according to the manufacturer's instructions (Easy Path, SP, Brazil). The sequencing reactions were performed using the DYEnamic ET Dye Terminator Cycle Sequencing Kit (GE Healthcare, Buckinghamshire, UK) and were loaded onto the MegaBACE 1000 DNA sequencer (GE Healthcare). The forward and reverse sequences were edited, assembled using the DNA Baser Sequence Assembler software, compared with bacterial-derived sequences deposited in the NCBI database (www.ncbi.nlm.nih.gov) and analyzed using the Basic Local Alignment Search Tool (BLAST; http:// blast.ncbi.nlm.nih.gov).

\section{Macrorestriction-Pulsed-Field Gel Electrophoresis Analysis}

The DNA macrorestriction followed by pulsed-field gel electrophoresis (PFGE) was performed on mecA- 
Table 1. Minimal inhibitory concentration (MIC) of 10 antimicrobial agents as determined by the Etest for Staphylococcus aureus and CNS isolated from bovine milk samples in Brazil

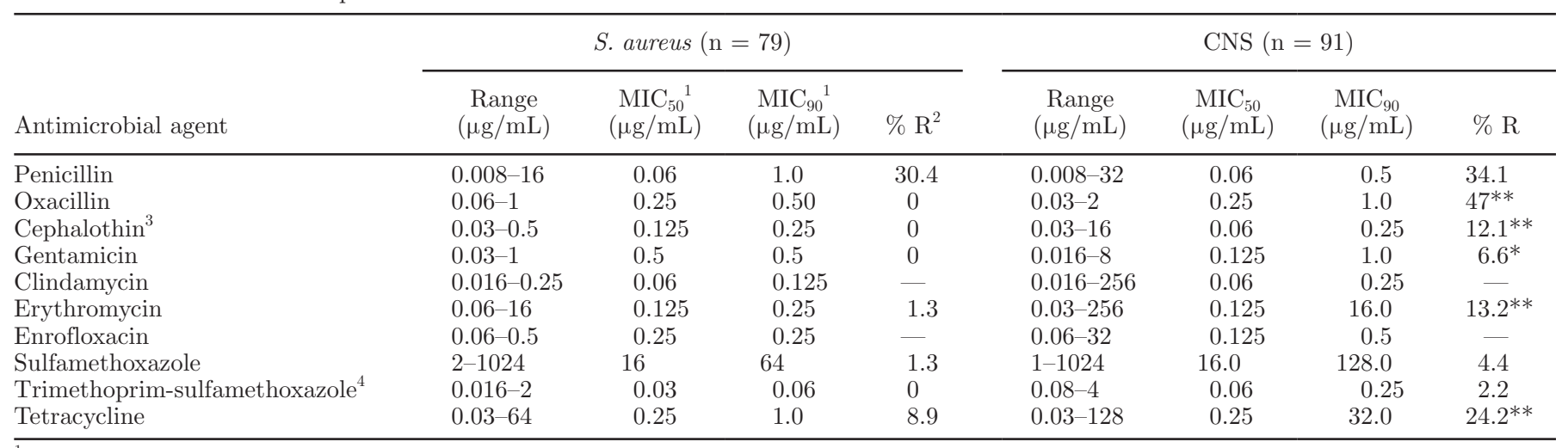

${ }^{1}$ Concentration of each antimicrobial agent able to inhibit the growth of 50 and $90 \%$ of the isolates $=\mathrm{MIC}_{50}$ and $\mathrm{MIC}_{90}$, respectively.

${ }^{2}$ Resistance was determined according CLSI (2013b) breakpoints.

${ }^{3}$ Resistance to cephalothin for CNS included the 10 mecA-positive isolates.

${ }^{4}$ Only the trimethoprim portion of the 1:19 combination is displayed.

*Denotes a significant difference in the number of resistant isolates of CNS as opposed to the number of resistant $S$. aureus isolates at $P \leq 0.05$ or $* *$ at $P \leq 0.01$ as determined by the chi-squared test.

positive staphylococci according to McDougal et al. (2003). Electrophoresis of SmaI-digested samples was performed on the CHEF-DRII (Bio-Rad, Hercules, CA) through $1.5 \%$ (wt/vol) electrophoresis-grade agarose (Sigma) under the following conditions: running time $23 \mathrm{~h}$, temperature $14^{\circ} \mathrm{C}, 6 \mathrm{~V} / \mathrm{cm}$, initial pulse time 5 $\mathrm{s}$, final pulse time $40 \mathrm{~s}$. Salmonella enterica serovar Braenderup (ATCC BAA 664) cleaved with the XbaI enzyme was used as a molecular weight marker. The gels were stained with ethidium bromide $(0.5 \mu \mathrm{g} / \mathrm{mL})$, and the DNA was visualized by UV transillumination. The image was captured under UV light in a photo documentation system (Eagle Eye II, Stratagene, La Jolla, CA).

Macrorestriction patterns were analyzed both visually and by computer-aided methods. The visual genetic relationship among the isolates was evaluated following the criteria of Tenover et al. (1995). The PFGE patterns that differed by more than 7 bands were recorded as distinct types and were identified with a different capital letter. Patterns that differed by 2 to 6 bands were assigned as subtypes and were identified with a capital letter followed by an Arabic numeral. A database containing all of the SmaI PFGE patterns was created using the Bionumerics software v. 6.0 (Applied Maths, Sint-Martens-Latem, Belgium), where band patterns over the gel were normalized and compared. Cluster analysis was performed by the Dice correlation coefficient and the unweighted pair group with a mathematical average (UPGMA) clustering algorithm, with a position tolerance of 1.0 and $0.5 \%$ optimization.

\section{RESULTS}

The concentration of each antimicrobial agent able to inhibit the growth of 50 and $90 \%$ of the isolates $\left(\mathbf{M I C}_{50}\right.$ and $\mathbf{M I C}_{90}$, respectively) results and the resistance profiles observed are summarized in Table 1 . The MIC values obtained with the control strain (ATCC 29213) were found to be within the expected ranges on all occasions for all antimicrobial agents tested (Supplemental Tables S1 and S2; http://dx.doi.org/10.3168/ jds.2015-9931).

All S. aureus isolates were susceptible to oxacillin, cephalothin, gentamicin, and trimethoprim-sulfamethoxazole, and $68 \%(\mathrm{n}=54)$ were susceptible to all antimicrobials tested. The highest resistance rates were observed for penicillin $(\mathrm{n}=24 ; 30.4 \%)$ and tetracycline ( $\mathrm{n}=7 ; 8.9 \%)$. One $S$. aureus isolate was resistant to erythromycin, and another one showed resistance to sulfamethoxazole. Among the S. aureus isolates resistant to penicillin, $16(20.2 \%)$ were resistant only to penicillin, $7(8.9 \%)$ to penicillin and tetracycline, and $1(1.3 \%)$ to penicillin and erythromycin. None of the $S$. aureus isolates showed MDR (Supplemental Table S3; http://dx.doi.org/10.3168/jds.2015-9931).

The CNS isolates showed susceptibility patterns similar to $S$. aureus for penicillin (n $=31 ; 34.1 \%$ resistance), sulfamethoxazole ( $\mathrm{n}=4 ; 4.4 \%$ resistance), and trimethoprim-sulfamethoxazole $(\mathrm{n}=2 ; 2.2 \%$ resistance). However, as opposed to the number of $S$. aureus isolates, the CNS isolates showed less susceptibility for cephalothin, erythromycin, oxacillin, and tetracycline 

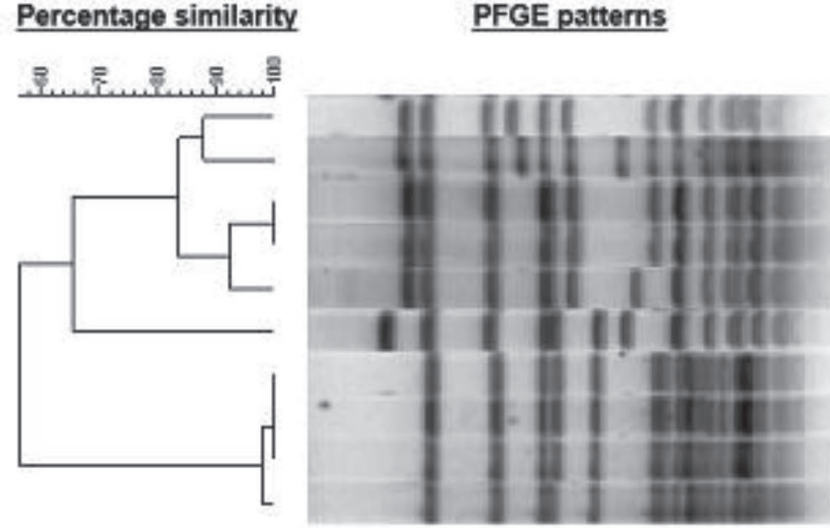

PFGE patterns $\underline{\text { ID }}$

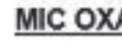

$\begin{array}{lll}\text { 225-MG } & 0.75 & \text { GN*-TT } \\ 915-S C & 1.5 & \text { GN*-TT } \\ 891-S C & 1.5 & \text { GN*-TT } \\ 896-S C & 2.0 & \text { GN*-TT } \\ 903-S C & 1.0 & \text { GN*-SXT*-TT } \\ 651-M G & 0.75 & \text { NONE } \\ 810-P R & 0.75 & \text { ER-SUL-TT } \\ 811-P R & 0.5 & \text { ER-TT } \\ 812-P R & 0.5 & \text { ER-TT } \\ 831-P R & 0.38 & \text { ER-TT }\end{array}$

$\underline{\text { sccmec type }}$

$\underline{\text { PFGE type } \underline{b l a Z}}$

Figure 1. Phenotypic and genotypic traits of Staphylococcus epidermidis harboring the mecA gene: dendrogram representing relatedness, pulsed-field gel electrophoresis (PFGE) patterns, isolate identification (ID), oxacillin minimal inhibitory concentration (MIC-OXA $\mu \mathrm{g} / \mathrm{mL}$ ), $S C C m e c$ type, presence $(+)$ or absence $(-)$ of blaZ gene, and co-resistance $(\mathrm{GN}=$ gentamicin, $\mathrm{TT}=$ tetracycline, $\mathrm{SXT}=$ trimethoprim-sulfamethoxazole, SUL = sulfamethoxazole, and ER = erythromycin; asterisk denotes an intermediate level of resistance). The PGFE types were defined based on SmaI-digested chromosomal DNA banding patterns and criteria of Tenover et al. (1995).

$(P \leq 0.01)$, and for gentamicin $(P \leq 0.05)$. The number of CNS isolates susceptible to all tested antimicrobials (n $=45 ; 49.5 \%)$ was lower than found for $S$. aureus $(P$ $\leq 0.05)$. Of the CNS resistant to one or more antimicrobial ( $\mathrm{n}=46 ; 50.5 \%), 18(19.8 \%)$ were resistant to 1 antimicrobial agent only, $11(12 \%)$ were resistant to 2 antimicrobials, and $17(18.7 \%)$ were resistant to 3 or more. Fifteen out of 91 CNS (16.5\%) showed MDR.

Susceptibility to oxacillin and cefoxitin was used to detect the methicillin-resistance phenotype. Oxacillin resistance was detected in $25 \mathrm{CNS}$ isolates (i.e., MIC $\geq 0.5 \mu \mathrm{g} / \mathrm{mL}$ ). In addition, 18 isolates with MIC equal to $0.38 \mu \mathrm{g} / \mathrm{mL}$ were included among the resistant isolates. Thus, the total number of oxacillin-resistant CNS was 43 isolates $(47 \%)$. Of these, only 10 were resistant to cefoxitin by the disk diffusion test. These included 9 CNS with a MIC ranging from 0.5 to $2.0 \mu \mathrm{g} / \mathrm{mL}$ and one (isolate 831) with a MIC equal to $0.38 \mu \mathrm{g} / \mathrm{mL}$.

The 25 CNS isolates with an oxacillin MIC $\geq 0.5 \mu \mathrm{g} /$ $\mathrm{mL}$ and 1 isolate resistant to cefoxitin (oxacillin MIC of $0.38 \mu \mathrm{g} / \mathrm{mL}$ ) were identified based on sequence analysis of the $16 \mathrm{~S}$ rRNA gene as S. epidermidis (10), S. chromogenes (2), S. lentus (1), S. saprophyticus (5), S. sciuri (2), and S. xylosus (3). Three isolates showed 99 to $100 \%$ coincidental similarity with the sequences of 2 species. They were classified as S. succinus or S. saprophyticus (isolates 901 and 916) and $S$. saprophyticus or S. xylosus (isolate 948).

Ten $(5.9 \%)$ out of the 170 staphylococci tested by PCR were positive for the mecA gene. Amplification reactions using primers described by Murakami et al. (1991) and Mehrotra et al. (2000) generated amplicons of the expected sizes. The DNA sequencing confirmed the identity of the 533-bp PCR products obtained using the primers described by Murakami et al. (1991) for the mecA gene of the 10 isolates. Nine isolates showed PCR products with $100 \%$ similarity, and one isolate showed $99 \%$ similarity. These 10 mecA-positive CNS were the same isolates that were resistant to cefoxitin by the disk diffusion test. All mecA-positive CNS were identified as S. epidermidis and considered as resistant to all tested $\beta$-lactam antimicrobials, regardless of the MIC result.

One mecA-positive $S$. epidermidis was only resistant to $\beta$-lactam antimicrobials, whereas all of the other 9 were MDR. The predominant co-resistance was found for tetracycline, present in 8 out of 9 isolates. Other co-resistances were found: erythromycin (4 isolates) and sulfamethoxazole (1). Six isolates were classified in the intermediate category for gentamicin (5) and trimethoprim $\times$ sulfamethoxazole (1), which were included among the co-resistances (Figure 1).

The PCR for the bla $Z$ and mecC genes was carried out on the $25 \mathrm{CNS}$ isolates (oxacillin MIC $\geq 0.5 \mu \mathrm{g} /$ $\mathrm{mL}$ ) and on the mecA-positive 831 isolate (oxacillin MIC $\geq 0.38 \mu \mathrm{g} / \mathrm{mL}$ ). Twelve isolates showed amplification products corresponding to the expected size of the blaZ gene. Nine of them were mecA-positive and 3 were mecA-negative, identified as $S$. chromogenes (2) and S. xylosus (1). The DNA sequencing of the fragments confirmed the identity with the blaZ gene with 99 to $100 \%$ similarity. None of these 26 CNS isolates showed a PCR product for the mecC gene. Two isolates phenotypically resistant to oxacillin (MIC values of 1.0 and $1.5 \mu \mathrm{g} / \mathrm{mL}$ ), identified as Staphylococcus sciuri, showed amplification products with similar size as expected for 
the mec $C$ gene. These products were not mec $C$, but a gene with $99 \%$ identity with the previously reported mecA-like gene in S. sciuri.

The $S C C m e c$ types of the 10 mecA-positive $S$. epidermidis were designated as type I (3 isolates), IV (4 isolates), and V (2 isolates), with one not able to be typed (Figure 1).

The DNA macrorestriction results of the S. epidermidis isolates carrying the mecA gene are shown in Figure 1. Three pulsotypes were found: A (3 isolates), B (2 isolates), and $\mathrm{C}$ (one isolate). Four isolates closely related to pulsotypes A and B were classified as subtype A1 and subtypes B1, B2, and B3. The pulsotype A and the subtype A1 were found in S. epidermidis from the same state (Paraná), the B and subtypes B1 and B2 were found in isolates from the State of Santa Catarina, and the $\mathrm{C}$ and subtype $\mathrm{B} 3$ were found in isolates from Minas Gerais State. The SCCmec cassette type IV was present in the isolates classified as pulsotype A and A1, the type $\mathrm{V}$ in pulsotype $\mathrm{B}$, and the type $\mathrm{I}$ in subtypes $\mathrm{B} 1, \mathrm{~B} 2$, and B3.

\section{DISCUSSION}

In this study, methicillin resistance was evaluated in staphylococci isolated from bovine milk. Although methicillin is no longer used clinically, resistance to the penicillinase-stable penicillins in staphylococci has been referred to as methicillin-resistant staphylococci or methicillin-resistant S. aureus (CLSI, 2013a). Methicillin-resistant staphylococci have already been observed in milk samples from dairy cattle (Holmes and Zadoks, 2011), and surveillance of this resistance trait is important for public health and veterinary medicine.

The staphylococci tested in this study could not be characterized as a random sampling of staphylococci isolated from bovine milk. As we wanted to look into the methicillin resistance, the isolates were selected among staphylococci that showed oxacillin inhibition zone diameter of $\leq 13 \mathrm{~mm}$ for $S$. aureus and of $\leq 18 \mathrm{~mm}$ for CNS in disk diffusion test. Thus, isolates only resistant to antimicrobials other than oxacillin were not included. Taking this into consideration, the comparison of our results with other studies should be interpreted with caution because differences may occur due to the selection criteria.

The most resistance was observed against penicillin in both $S$. aureus and CNS isolates. Penicillin or $\beta$-lactam antibiotics are widely used for the intramammary treatment of bovine mastitis, and this may be related to the increase in penicillin resistance. Rajala-Schultz et al. (2004) indicated that resistance to penicillin in CNS was associated with antimicrobial use in the study herd as the proportion of resistant bacteria was ap- proximately $13 \%$ higher among multiparous than in primiparous cows, although the difference was not statistically significant. Saini et al. (2012) collected data on antimicrobial use and resistance in $S$. aureus from intramammary infection cases on 89 dairy farms in 4 regions of Canada. They found that dry cow therapy with penicillin-novobiocin administration was associated with penicillin and ampicillin resistance. Systemic administration of penicillin was also associated with penicillin resistance.

From the data available in the literature on the antimicrobial susceptibility of mastitis pathogens, it can be observed that staphylococci susceptibility to penicillin varies according to country or region. For example, the frequency of penicillin resistance of $S$. aureus from bovine milk ranged from $4 \%$ to more than $80 \%$ (Shi et al., 2010; Persson et al., 2011), and of CNS from $22.3 \%$ to approximately 40\% (Botrel et al., 2010; Kalmus et al., 2011).

With the exception of penicillin and tetracycline, $S$. aureus isolates investigated in this study were susceptible to most antimicrobial agents tested. The $\mathrm{MIC}_{50}$ for $S$. aureus isolates to penicillin was comparable to that reported by Persson et al. (2011) in Sweden and was lower than those reported by Nunes et al. (2007) in Portugal and Moroni et al. (2006) in Italy. For tetracycline, the $\mathrm{MIC}_{50}$ and $\mathrm{MIC}_{90}$ were lower than those reported in the United States (Oliveira et al., 2012) and in Sweden (Bengtsson et al., 2009; Persson et al., 2011). However, the tetracycline MIC range found in our study was greater than reported by these authors. This finding suggests that the investigated $S$. aureus population is being exposed to this antimicrobial, and if the selective pressure continues, the number of resistant bacteria may increase in the future.

In addition to increased resistance of CNS compared with $S$. aureus isolates, we found that the CNS resistance profiles were more diversified, as $18.7 \%$ of the isolates were resistant to 3 or more antimicrobial agents. This means that $37 \%$ of the isolates showed resistance to at least one antimicrobial agent. Other studies have also highlighted an increased resistance of CNS isolates to antimicrobials. Among CNS isolates, $20.1 \%$ were found to be resistant to 2 or more antibiotics, as reported by Rajala-Schultz et al. (2004), and MDR frequencies of 7.9 and $10.6 \%$ were described by Rajala-Schultz et al. (2004) and Sampimon et al. (2011), respectively. With the exception of the resistance to penicillin, lower rates of resistance in CNS were reported by Botrel et al. (2010), Persson et al. (2011), and Piessens et al. (2012). Few studies in Brazil have analyzed the antimicrobial susceptibility profile of staphylococci isolated from bovine milk using MIC, and the majority of them used the disk diffusion 
method. Despite the methodological differences, our results showed lower penicillin-resistance rates (Silva et al., 2014; da Costa Krewer et al., 2015).

Coagulase-negative staphylococci are composed of a heterogeneous group of bacteria that includes different species of staphylococci. Typically, they are considered as secondary mastitis pathogens rarely involved in moderate or severe clinical cases (Vanderhaeghen et al., 2014). Some species seem more adapted to the mammary gland, whereas others are more prevalent in the environment and rarely cause intramammary infection. It has been shown that antimicrobial resistance among the different species of CNS varies and was more frequently reported in species with environmental traits (Piessens et al., 2012). Unlike the cows infected with $S$. aureus, cows infected by CNS are less likely to be discarded as a mastitis control measure. This indicates a greater exposure for the CNS present in the herd to the antimicrobials used for the treatment of mastitis or other diseases such as lameness, respiratory, or reproductive problems. An augmented exposure to antimicrobials can lead to an increase in resistant strains and consequently to the diversity we observed in the resistance profile of the isolates.

In relation to the antimicrobial clindamycin, without the breakpoints defined by CLSI (2013b), we found that the $\mathrm{MIC}_{50}$ and $\mathrm{MIC}_{90}$ results for $S$. aureus and CNS were comparable to those described by Persson et al. (2011). However, we found higher MIC range values for CNS. Piessens et al. (2012), who also used the Etest, reported enrofloxacin $\mathrm{MIC}_{50}$ and $\mathrm{MIC}_{90}$ of 0.125 and $0.25 \mu \mathrm{g} / \mathrm{mL}$ for CNS, respectively. In our study, a greater $\mathrm{MIC}_{90}(0.5 \mu \mathrm{g} / \mathrm{mL})$ was found.

A large number of CNS isolates were found to be phenotypically resistant to oxacillin (MIC $\geq 0.5 \mu \mathrm{g} /$ $\mathrm{mL}$ ). This number was enlarged by the inclusion of isolates that showed an oxacillin MIC equal to $0.38 \mu \mathrm{g} /$ $\mathrm{mL}(\mathrm{n}=18)$, following the recommendation of rounding the half-log MIC values to the next higher value on the standard 2-fold dilution series (Schwarz et al., 2010). The phenotypic susceptibility testing to oxacillin has been used to predict resistance to methicillin, and more recently, the cefoxitin disk diffusion test has been recommended for this purpose (CLSI, 2013a). Our results have shown that the same $10 \mathrm{CNS}$ isolates that exhibited resistance to cefoxitin amplified the mecA gene by PCR. As the phenotypic expression of oxacillin resistance is heterogeneous (i.e., the cells that express highest resistance may represent a small fraction of the bacterial population), testing for the $m e c A$ gene is the most accurate way to predict resistance to oxacillin (CLSI, 2013a). Our results showed that the cefoxitin disk diffusion method was $100 \%$ sensitive and $100 \%$ specific to indicate the presence of the mecA gene.
One isolate with an oxacillin MIC value of $0.38 \mu \mathrm{g} /$ $\mathrm{mL}$ was positive for mecA, whereas all of the other $m e c A$-positive isolates showed an oxacillin MIC in the range of 0.5 to $2.0 \mu \mathrm{g} / \mathrm{mL}$ (Figure 1). All $10 \mathrm{CNS}$ isolates carrying the mecA gene were identified as $S$. epidermidis. We found $13 \mathrm{CNS}$ isolates that were resistant to oxacillin but were mecA- and blaZ-negative (oxacillin $\mathrm{MIC} \geq 0.5-2.0 \mu \mathrm{g} / \mathrm{mL}$ ). A possible mechanism to explain the phenotype of resistance to oxacillin in the absence of the mecA gene would be the overproduction of $\beta$-lactamase. However, other mechanisms may be involved in the expression of oxacillin resistance such as the production of a new methicillinase, change in the penicillin-binding protein subtypes, or increased levels of resistance to cadmium (Massidda et al., 2006; Park et al., 2013). It has been shown that mutations in the penicillin-binding proteins 1,2 , and 3 may lower their affinity for the $\beta$-lactam antibiotics (Ba et al., 2014), mediating oxacillin resistance in the absence of mecA or mecC. Other studies are necessary to investigate the oxacillin resistance mechanism in the 13 mecA- and blaZ-negative CNS isolates we found in this present study.

The CNS isolates showing oxacillin MIC values $\geq 0.5$ $\mu \mathrm{g} / \mathrm{mL}$ that did not amplify mecA by PCR were tested for the presence of $m e c C$ gene, but it was not detected. To date, no reports were found on mec $C$ detection in staphylococci isolated from bovine mastitis in Brazil (Silva et al., 2014).

The mecA-like gene that was amplified using mecC primers in $2 S$. sciuri isolates showed $88 \%$ similarity on the overall AA sequence and $80 \%$ similarity to the DNA sequence to the mecA gene (Becker et al., 2014). Most S. sciuri isolates carrying the mecA-like gene are susceptible to $\beta$-lactam antibiotics, but the presence of this gene along with the mecA gene may lead to resistance to oxacillin. Additionally, a high rate of transcription of a mecA-like gene caused by a change in a nucleotide or the insertion of the IS256 element can lead to resistance to oxacillin/methicillin in the $S$. sciuri strains (Rahman et al., 2005).

The typing of the SCCmec cassette, combined with PFGE, provided information on the epidemiological profile of the S. epidermidis isolates. The 3 SCCmec types (I, IV, and V) found were described previously in Staphylococcus spp. isolated from animals (Holmes and Zadoks, 2011). The SCCmec type IV was found in 4 isolates of different regions of the same state (Paraná, Brazil). The relatively smaller size of this cassette (20-24 kb) compared with other types of SCCmec may facilitate its transfer among staphylococci (Becker et al., 2014). The pulsotypes B and B1 were present in the neighboring state (Santa Catarina), also in the South region, whereas the pulsotype B3 was found in Minas 
Gerais State, which is located approximately 1,000 km away. This distribution of common methicillin-resistant S. epidermidis pulsotypes indicates a wide geographical spread of the isolates.

Staphylococcus epidermidis is considered one of the 5 main frequently isolated species of CNS from bovine milk (Vanderhaeghen et al., 2014). The presence of methicillin-resistant $S$. epidermidis in bovine milk samples is a matter of concern, as they may act as a reservoir of genetic elements carrying antimicrobial resistance. Due to the mobile nature of the SCCmec elements, they can be transferred to other species of staphylococci, including $S$. aureus, contributing to the emergence of methicillin-resistant $S$. aureus. The transfer of resistance determinants may occur not only for $\beta$-lactams but also for other classes of antibiotics (Becker et al., 2014).

Knowledge about the phenotypic antimicrobial resistance of the staphylococci isolated in a region is important for adoption of appropriate therapeutic procedures. The cefoxitin disk diffusion method was sensitive and specific for the detection of CNS carriers of mecA and should be used in routine microbiological diagnosis of mastitis. This practice would detect staphylococci bearing the mecA gene, which implies that they are resistant to almost all $\beta$-lactam agents. This could help to reduce the dissemination of antimicrobial resistance and to determine strategies for the prevention, treatment, and control of staphylococcal infections in animals and man.

\section{ACKNOWLEDGMENTS}

This study was supported by the Conselho Nacional de Desenvolvimento Científico e Tecnológico (CNPq; grant 578430/2008-8 to M. A. V. Brito), Coordenação de Aperfeiçoamento de Pessoal de Nível Superior (CAPES; fellowship to F. F. Santos), and the Brazilian Agricultural Research Corporation (Embrapa). We thank E. K. Vaz (Santa Catarina State University, UDESC, Lages, SC, Brazil), G. M. Costa (Federal University of Lavras, UFLA, Lavras, MG, Brazil), L. A. Martins (University Paranaense, UNIPAR, Umuarama, PR, Brazil), M. V. Santos (São Paulo State University, USP, Pirassununga, SP, Brazil), M. Cardoso (Federal University of Rio Grande do Sul, UFRGS, Porto Alegre, RS, Brazil), and R. A. Motta (Rural Federal University of Pernambuco, UFRPE, Recife, PE, Brazil) for providing the staphylococci.

\section{REFERENCES}

Ba, X., E. M. Harrison, G. F. Edwards, M. T. G. Holden, A. R. Larsen, A. Peterson, R. L. Skov, S. J. Peacock, J. Parkhill, G. K.
Paterson, and M. A. Holmes. 2014. Novel mutations in penicillinbinding protein in clinical Staphylococcus aureus isolates that are methicillin resistant on susceptibility testing, but lack the mec gene. J. Antimicrob. Chemother. 69:594-597.

Becker, K., B. Ballhausen, R. Köck, and A. Kriegeskorte. 2014. Methicillin resistance in Staphylococcus isolates: The "mec alphabet" with specific consideration of mecC, a mec homolog associated with zoonotic S. aureus lineages. Int. J. Med. Microbiol. 304:794-804.

Bengtsson, B., H. E. Unnerstad, T. Ekman, K. Artursson, M. NilssonOst, and K. P. Waller. 2009. Antimicrobial susceptibility of udder pathogens from cases of acute clinical mastitis in dairy cows. Vet. Microbiol. 136:142-149.

Botrel, M.-A., M. Haenni, E. Morignat, P. Sulpice, J.-Y. Madec, and D. Calavas. 2010. Distribution and antimicrobial resistance of clinical and subclinical mastitis pathogens in dairy cows in RhôneAlpes, France. Foodborne Pathog. Dis. 7:479-487.

CLSI (Clinical and Laboratory Standards Institute). 2013a. Performance standards for antimicrobial disk and dilution susceptibility tests for bacteria isolated from animals; approved standard, 4th ed. CLSI document VET01-A4. Clin. Lab. Stand. Inst., Wayne, PA.

CLSI (Clinical and Laboratory Standards Institute). 2013b. Performance standards for antimicrobial disk and dilution susceptibility tests for bacteria isolated from animals; second informational supplement. CLSI document VET01-S2. Clin. Lab. Stand. Inst., Wayne, PA.

da Costa Krewer, C., E. S. Amanso, G. V. Gouveia, R. L. Souza, M. M. Costa, and R. A. Mota. 2015. Resistance to antimicrobials and biofilm formation in Staphylococcus spp. isolated from bovine mastitis in the Northeast of Brazil. Trop. Anim. Health Prod. $47: 511-518$.

Gao, J., M. Ferreri, X. Q. Liu, L. B. Chen, J. L. Su, and B. Han. 2011. Development of multiplex polymerase chain reaction assay for rapid detection of Staphylococcus aureus and selected antibiotic resistance genes in bovine mastitic milk samples. J. Vet. Diagn. Invest. 23:894-901.

García-Álvarez, L., M. T. G. Holden, H. Lindsay, C. R. Webb, D. F. J. Brown, M. D. Curran, E. Walpole, K. Brooks, D. J. Pickard, C. Teale, J. Parkhill, S. D. Bentley, G. F. Edwards, E. K. Girvan, A. M. Kearns, B. Pichon, R. L. R. Hill, A. R. Larsen, R. L. Skov, S. J. Peacock, D. J. Maskell, and M. A. Holmes. 2011. Methicillinresistant Staphylococcus aureus with a novel mecA homologue in human and bovine populations in the UK and Denmark: A descriptive study. Lancet Infect. Dis. 11:595-603.

Holmes, M. A., and R. N. Zadoks. 2011. Methicillin resistant S. aureus in human and bovine mastitis. J. Mammary Gland Biol. Neoplasia $16: 373-382$.

IWG-SCC (International Working Group on the Classification of Staphylococcal Cassette Chromosome Elements). 2009. Classification of staphylococcal cassette chromosome mec (SCCmec): guidelines for reporting novel SCCmec elements. Antimicrob. Agents Chemother. 53:4961-4967.

Jaffe, R. I., J. D. Lane, S. V. Albury, and D. M. Niemeyer. 2000. Rapid extraction from and direct identification in clinical samples of methicillin-resistant staphylococci using the PCR. J. Clin. Microbiol. 38:3407-3412.

Kalmus, P., B. Aasmae, A. Kärssin, T. Orro, and K. Kask. 2011. Udder pathogens and their resistance to antimicrobial agents in dairy cows in Estonia. Acta Vet. Scand. 53:4-10.

Lange, C. C., M. A. V. P. Brito, D. R. L. Reis, M. A. Machado, A. S. Guimarães, A. L. S. Azevedo, E. B. Salles, M. C. T. Alvim, F. S. Silva, and I. R. Meurer. 2015. Species-level identification of staphylococci isolated from bovine mastitis in Brazil using partial 16S rRNA sequencing. Vet. Microbiol. 176:382-388.

Massidda, O., M. Mingoia, D. Fadda, M. B. Whalen, M. P. Montanari, and P. E. Varaldo. 2006. Analysis of the beta-lactamase plasmid of borderline methicillin-susceptible Staphylococcus aureus: Focus on bla complex genes and cadmium resistance determinants $c a d D$ and cadX. Plasmid 55:114-127.

McDougal, L. K., C. D. Steward, G. E. Killgore, J. M. Chaitram, S. K. McAllister, and F. C. Tenover. 2003. Pulsed-field gel electro- 
phoresis typing of oxacillin-resistant Staphylococcus aureus isolates from the United States: Establishing a national database. J. Clin. Microbiol. 41:5113-5120.

Mehrotra, M., G. Wang, and W. M. Johnson. 2000. Multiplex PCR for detection of genes for Staphylococcus aureus enterotoxins, exfoliative toxins, toxic shock syndrome toxin 1 , and methicillin resistance. J. Clin. Microbiol. 38:1032-1035.

Milheiriço, C., D. C. Oliveira, and H. de Lencastre. 2007. Update to the multiplex PCR strategy for assignment of mec element types in Staphylococcus aureus. Antimicrob. Agents Chemother. 51:3374-3377.

Moroni, P., G. Pisoni, M. Antonini, R. Villa, P. Boettcher, and S. Carli. 2006. Antimicrobial drug susceptibility of Staphylococcus aureus from subclinical bovine mastitis in Italy. J. Dairy Sci. 89:2973-2976.

Murakami, K., W. Minamide, K. Wada, E. Nakamura, H. Teraoka, and S. Watanabe. 1991. Identification of methicillin-resistant strains of staphylococci by polymerase chain reaction. J. Clin. Microbiol. 29:2240-2244.

NMC. 2004. Microbiological Procedures for the Diagnosis of Bovine Udder Infection and Determination of Milk Quality. 4th ed. National Mastitis Council, Verona, WI.

Nunes, S. F., R. Bexiga, L. M. Cavaco, and L. Vilela. 2007. Antimicrobial susceptibility of Portuguese isolates of Staphylococcus aureus and Staphylococcus epidermidis in subclinical bovine mastitis. J. Dairy Sci. 90:3242-3246.

Oliveira, L., H. Langoni, C. Hulland, and P. L. Ruegg. 2012. Minimum inhibitory concentrations of Staphylococcus aureus recovered from clinical and subclinical cases of bovine mastitis. J. Dairy Sci. 95:1913-1920.

Park, J., R. M. Friendship, J. S. Weese, Z. Poljak, and C. E. Dewey 2013. An investigation of resistance to $\beta$-lactam antimicrobials among staphylococci isolated from pigs with exudative epidermitis. BMC Vet. Res. 9:211-218.

Persson, Y., A.-K. Nyman, and U. Gronlund-Andersson. 2011. Etiology and antimicrobial susceptibility of udder pathogens from cases of subclinical mastitis in dairy cows in Sweden. Acta Vet. Scand. $53: 36-43$.

Piessens, V., S. De Vliegher, B. Verbist, G. Braem, A. van Nuffel, L. de Vuyst, M. Heyndrickx, and E. van Coillie. 2012. Characterization of coagulase-negative Staphylococcus species from cows' milk and environment based on bap,icaA, and mecA genes and pheno- typic susceptibility to antimicrobials and teat dips. J. Dairy Sci 95:7027-7038

Rahman, M. T., N. Kobayashi, M. M. Alam, and M. Ishino. 2005. Genetic analysis of mecA homologues in Staphylococcus sciuri strains derived from mastitis in dairy cattle. Microb. Drug Resist. 11:205-214.

Rajala-Schultz, P. J., K. L. Smith, J. S. Hogan, and B. C. Love. 2004 Antimicrobial susceptibility of mastitis pathogens from first lactation and older cows. Vet. Microbiol. 102:33-42.

Saini, V., J. T. McClure, D. T. Scholl, T. J. DeVries, and H. W. Barkema. 2012. Herd-level association between antimicrobial use and antimicrobial resistance in bovine mastitis Staphylococcus aureus isolates on Canadian dairy farms. J. Dairy Sci. 95:1921-1929.

Sampimon, O. C., T. J. G. M. Lam, D. J. Mevius, Y. H. Schukken, and R. N. Zadoks. 2011. Antimicrobial susceptibility of coagulasenegative staphylococci isolated from bovine milk samples. Vet. Microbiol. 150:173-179.

Schwarz, S., P. Silley, S. Simjee, N. Woodford, E. van Duijkeren, A. P. Johnson, and W. Gaastra. 2010. Assessing the antimicrobial susceptibility of bacteria obtained from animals. Vet. Microbiol. 141:1-4.

Shi, D., Y. Hao, A. Zhang, and X. Fan. 2010. Antimicrobial resistance of Staphylococcus aureus isolated from bovine mastitis in China. Transbound. Emerg. Dis. 57:221-224.

Silva, N. C. C., F. F. Guimarães, M. P. Manzi, E. Gómez-Sanz, P. Gómez, J. P. Araújo-Júnior, H. Langoni, V. L. M. Rall, and C. Torres. 2014. Characterization of methicillin-resistant coagulasenegative staphylococci in milk from cows with mastitis in Brazil. Antonie van Leeuwenhoek 106:227-233

Tenover, F. C., R. D. Arbeit, R. V. Goering, P. A. Mickelsen, B. E. Murray, D. H. Persing, and B. Swaminathan. 1995. Interpreting chromosomal DNA restriction patterns produced by pulsed-field gel electrophoresis: Criteria for bacterial strain typing. J. Clin. Microbiol. 33:2233-2239.

Vanderhaeghen, W., S. Piepers, F. Leroy, E. Van Coillie, F. Haesebrouck, and S. De Vliegher. 2014. Effect, persistence, and virulence of coagulase-negative Staphylococcus species associated with ruminant udder health. J. Dairy Sci. 97:5275-5293.

Viguier, C., S. Arora, N. Gilmartin, K. Welbeck, and R. O'Kennedy. 2009. Mastitis detection: Current trends and future perspectives. Trends Biotechnol. 27:486-493. 